\title{
Study of Pipeline Penetration Based on CEL in Clay
}

\author{
Li Jia ${ }^{1, *}$, Liu Tao ${ }^{2,3}$, Jiang Jian ${ }^{1}$, Zheng Zhigang ${ }^{2}$, and Huang Hong ${ }^{2}$ \\ ${ }^{1}$ Shenzhen Tagen $<$ Group $>$ Co., Ltd,. 518034 Shenzhen, China \\ ${ }^{2}$ Shenzhen Yuetong Construction Engineering Co., Ltd,. 518019 Shenzhen, China \\ ${ }^{3}$ Shenzhen Tagen Engineering Technology Co., Ltd, 518034 Shenzhen, China
}

\begin{abstract}
In deep water, pipelines are usually laid directly on the seabed. During the laying process, the pipe typically penetrates into the seabed by a fraction of a diameter. The vertical embedment of pipeline and formation of berm during penetration have a significant effect on the pipeline stability. This study aims to investigate the vertical pipeline penetration at uniform and normal consolidated clay, by carrying out a series of numerical analyses, in which the coupled Eulerian-Lagrangian method (CEL) is incorporated to enable large deformation simulation. These analyses have been compared with collapse loads calculated using the theory solution. The results show that the CEL method is very suitable for simulating largedeformation pipesoil interaction.
\end{abstract}

\section{Introduction}

Submarine pipe is an important part of offshore oil and natural gas development. In deep water, it is no necessary to protect the submarine pipe, so they are not ditched or buried but laid directly on the seabed. Generally, for a typical single-hole submarine pipe, its subsidence depth is about $0.1 \sim 0.5$ times the pipe diameter during the laying process ${ }^{[1]}$. During the process of transporting oil and natural gas in the submarine pipe, it is necessary to apply certain temperature and pressure, and the joint action of temperature and pressure causes additional stress in the pipe. Due to the constraints of the foundation soil, the pipe cannot deform freely to release stress, when the accumulated stress value exceeds the binding force of the foundation soil on the pipe, the pipe will occur buckling (pipe buckling) or moving (pipe walking) phenomenon. The depth of self-subsidence is an important parameter to determine the lateral resistance and analyze the in-situ stability of pipes.

In the study of vertical subsidence of submarine pipe, according to the plastic solution, Murff et al. ${ }^{[2]}$ and Aubeny et al. ${ }^{[3]}$ considered the soil mass as a rigidplastic Tresca material and obtained the relationship between the normalized vertical force $V / D s_{u}$ and the normalized subsidence displacement $w / D$ of the wishedin-place (WIP). Merifield et al. ${ }^{[1]}$, Randolph and White et al. [4] also studied and obtained the results of the relationship between pipe subsidence depth and soil resistance in the case of WIP, and considered the characteristics of the $V-H$ envelope surface when the submarine pipe was subjected to a combination of vertical and horizontal forces.

However, Cathie et al. ${ }^{[5]}$ pointed out that the uplift of the soil mass will lead to a situation in which the subsidence resistance is greater than WIP during the subsidence of the submarine pipe, and the selfsubsidence process of the submarine pipe is actually a process in which the submarine pipe is gradually extruded into the soil mass (push-in-place, referred to as PIP in the following text), as shown in Fig.1. Since there is no exact theoretical solution to this problem, researchers usually study PIP by numerical simulation method. White et al. ${ }^{[6]}$ used the Remeshing and Interpolation Technique with Small Strain Model (RITSS for short) to analyze the PIP situation of submarine pipe. Wang et al. ${ }^{[7]}$ and Chatterjee et al. ${ }^{[8]}$ combined the strain rate and strain softening models to probe into the relationship between pipe subsidence depth and soil mass resistance in the case of PIP situation by using the RITSS method.

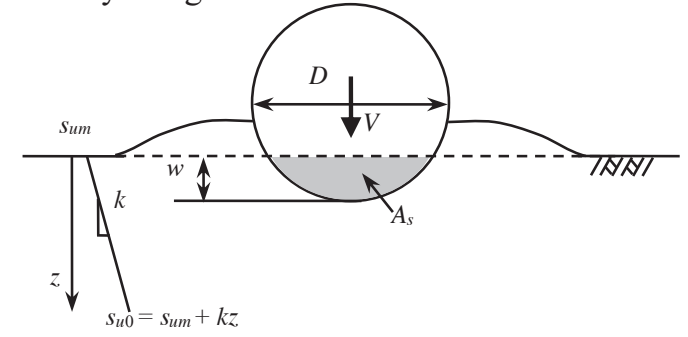

Fig.1. Schematic diagram of pipe self-subsidence

In this paper, Coupled Euler-Lagrange (CEL) Finite Element Method is adopted to study the PIP situation of submarine pipe self-subsidence. The relationship between the subsidence resistance and the subsidence displacement of the submarine pipe in both the nonheavy homogeneous clay and the normal heavy consolidated clay is obtained. The influence of unit weight and undrained shear strength on the selfsubsidence resistance of submarine pipe is discussed. The study results also show that the CEL finite element

\footnotetext{
*Corresponding author: li_jia@tju.edu.cn
} 
method has good applicability in simulating pipe-soil interaction, and can effectively simulate the large deformation between submarine pipe and soil mass.

\section{Theoretical Solution}

Accurate prediction of deep burying after pipe installation is the key to evaluate the lateral stability of pipe. In clay where homogeneous or undrained shear strength increases with depth, based on the traditional bearing capacity theory, many scholars have proposed the shaping theoretical solution of the vertical resistance of pipe by modifying the foundation shape ${ }^{[14,9]}$, which is expressed as follows:

$$
\begin{aligned}
\frac{V}{D s_{u 0}} & =N_{c}+N_{b} \frac{\gamma^{\prime} w}{s_{u 0}} \\
N_{b} & =f_{b} \frac{A_{s}}{D w}
\end{aligned}
$$

In the formula, $V$ is the vertical load the unit length of pipe, $D$ is the outside diameter of the pipe, $s_{u 0}$ is the undrained shear strength of the soil at the depth of the pipe, $N_{c}$ is the bearing capacity coefficient and $f_{b}$ is the buoyancy coefficient. Based on Archimedes' principle, the buoyancy coefficient $f_{b}=1$, while studies conducted by Merifield et al. ${ }^{[9]}$, Randolph and White ${ }^{[10]}$ have shown that it is more appropriate to take the buoyancy coefficient $f_{b}$ as 1.5 at this time due to the uplift that the soil mass will produce during the pipe subsidence; $A_{s}$ is the cross-sectional area of the pipe subsidence, as shown in Fig.1, the calculation formula is as:

$$
\begin{gathered}
A_{s}=\frac{D^{2}}{4}\left[\sin ^{-1}\left(\sqrt{4 \frac{w}{D}\left(1-\frac{w}{D}\right)}\right)-2\left(1-2 \frac{w}{D}\right) \sqrt{\frac{w}{D}\left(1-\frac{w}{D}\right)}\right] \\
\text { when } w / D \leqq 0.5 \\
A_{s}=\frac{D^{2}}{4}\left[\pi-\sin ^{-1}\left(\sqrt{4 \frac{w}{D}\left(1-\frac{w}{D}\right)}\right)-2\left(1-2 \frac{w}{D}\right) \sqrt{\frac{w}{D}\left(1-\frac{w}{D}\right)}\right] \\
\text { when } 0.5 \leqq w / D \leqq 1.0
\end{gathered}
$$

In the available studies, $N_{c}$ values mostly ignored the effects of soil mass uplift and soil mass heaviness and assumed that the pipe is pre-buried into the soil (WIP). It can be seen that the influence of soil mass heaviness and soil mass uplift on the vertical load is reflected in the $N_{b}$ term in formula (1). $N_{c}$ is related to the subsidence depth of the pipe, it is usually simplified to the form of a power function ${ }^{[1,3,9]}$, which is expressed as:

$$
N_{c}=a\left(\frac{w}{D}\right)^{b}
$$

In the formula: $w$ is the subsidence depth of pipe; $a$ and $b$ are fit coefficients, which are related to the roughness of pipe-soil interface and $k D / s_{u m}$. The values of the coefficients $a$ and $b$ are shown in Table 1, among them, $k D / s_{u m}=0$ means homogeneous soil; $k D / s_{u m}=\infty$ means undrained shear strength grows in a triangular shape with depth; and $k D / s_{u m}=0 \sim \infty$ means undrained shear strength grows in shape with depth.

Table 1. Values of a and $b$ for w/D $<0.5$ (Aubeny et al. ${ }^{[3]}$ )

\begin{tabular}{|c|c|c|c|}
\hline$k D /$ sum $_{\text { }}$ & roughness of pipe-soil interface & $\mathrm{a}$ & $\mathrm{b}$ \\
\hline 0 & smooth & 5.42 & 0.29 \\
\hline
\end{tabular}

\begin{tabular}{|c|c|c|c|}
\hline & rough & 7.41 & 0.37 \\
\hline \multirow{3}{*}{$\infty$} & smooth & 4.44 & 0.17 \\
\cline { 2 - 4 } & rough & 6.02 & 0.20 \\
\hline \multirow{2}{*}{$0 \sim \infty$} & smooth & 4.97 & 0.23 \\
\cline { 2 - 4 } & rough & 6.73 & 0.29 \\
\hline
\end{tabular}

\section{CEL Analysis}

\subsection{Basic Principle of CEL Method}

The Coupled Euler-Lagrange (CEL) Finite Element Method combines the advantages of Lagrangian Element Method and Euler Grid, while the grid is fixed and the material can flow freely in the grid when Euler Grid is adopted, which effectively solves many problems such as large deformation and material failure. At the same time, through the Coupled Euler-Lagrangian contact algorithm, the Lagrangian grid is used to obtain the accurate stress-strain response of the structure, which can accurately simulate the interaction between pipe and soil ${ }^{[1 \sim 13]}$.

In Coupled Euler-Lagrange Finite Element Method, the embodiment of Euler material is based on the fluid volume method. In this method, the trajectory of the material flowing in the grid is determined by calculating the Eulerian Volume Fraction (EVF) in each cell. If a cell is completely filled with material, the Euler Volume Fraction of this cell is $1(\mathrm{EVF}=1)$; if there is no material in a certain cell, then its $E V F=0$. If the total volume fraction of all materials in a cell is less than 1 , the remainder of the cell is automatically occupied by "empty" materials, it neither has mass nor strength. The contact between Euler Cuboid and Lagrange is usually discretized by a general contact Algorithm based on the penalty function method. The penalty contact method approximates the hardening pressure - interference relationship, allowing the Euler Cuboid to invade the Lagrange with a smaller amount of interference. The interface between the matter within the Lagrange grid region and the Euler matter is simulated by a generalized contact algorithm based on a penalty function method:

$$
F_{p}=k_{p} d_{p}
$$

In the formula, $F_{P}$ is the contact force between corresponding points on the interface; $d_{P}$ is penetration depth, $k_{P}$ is penalty stiffness, and its value is related to Lagrange and Euler dielectric material properties. Contact definition of the universal contact Algorithm allows a very automation, which can automatically specify the master and side surfaces in the contact surface, so it is well suited for highly nonlinear contact problems that involves large deformation.

\subsection{Non-heavy Homogeneous Soil}

The submarine pipe self-subsidence is calculated and analyzed in the non-heavy homogeneous clay foundation by using CEL finite element method. Among them, the pipe is simulated as Lagrange cell, which is regarded as rigid body in the analysis because of its large stiffness and small deformation during the subsidence process. 
The soil was simulated as an Euler cell with a calculation area of $10 D \times 8 D$. Considering the undrained characteristics during the subsidence of the submarine pipe, the ratio of elastic modulus and undrained shear strength was 500 by using the Tresca Yield Criterion, i.e., $E / s_{u}=500$ and Poisson's ratio was 0.49 . An empty cell with the height of $1.8 D$ above the soil mass is established to simulate the uplift of the seabed soil mass when the pipe subsides. The contact between the pipe soil is considered as two situations, smoothness and roughness. The finite element model is shown in Fig.2.

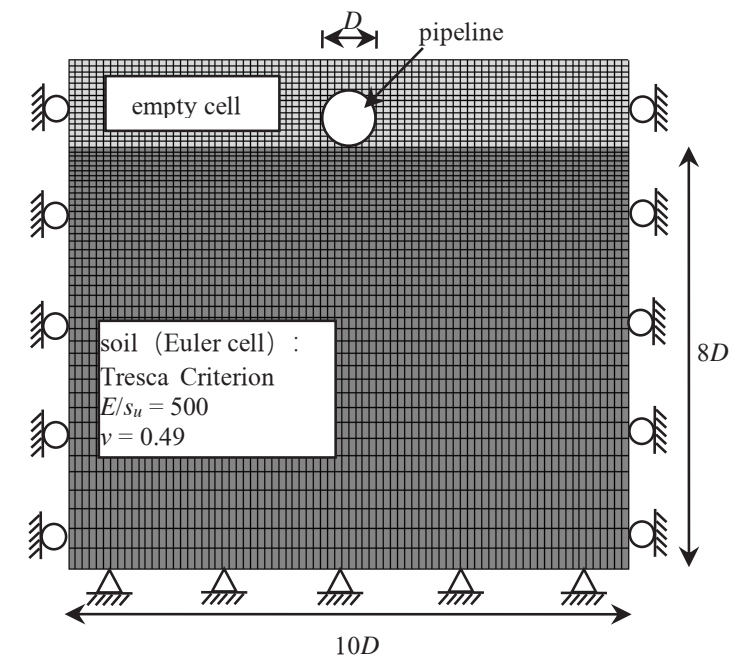

Fig.2 Finite Element Calculation Model

For the non-heavy soil, the theoretical solution of the submarine pipe subsidence resistance is given by formula (1) to remove the $N_{b}$ term of the effect of the self-weight of the soil mass, which is:

$$
\frac{V}{D s_{u 0}}=a\left(\frac{w}{D}\right)^{b}
$$

Moreover, by referring to the values of $a$ and $b$ in Table 1, for rough pipe-soil contact, $\mathrm{a}=7.41, \mathrm{~b}=0.37$; for smooth pipe-soil contact, $\mathrm{a}=5.42, \mathrm{~b}=0.29$. The calculated results by using the CEL method are compared with the theoretical formula. The calculated results are shown in Fig.3, it can be seen that the normalized vertical force $V / D s_{u}$ and the normalized subsidence displacement $w / D$ calculated by using the CEL finite element method are slightly smaller than those calculated by Randolph and Houlsby ${ }^{[14]}$, and are very close to those calculated by formula (7) and Merifield, etc. ${ }^{[9]}$, this also validates the reliability of the results calculated by CEL method.

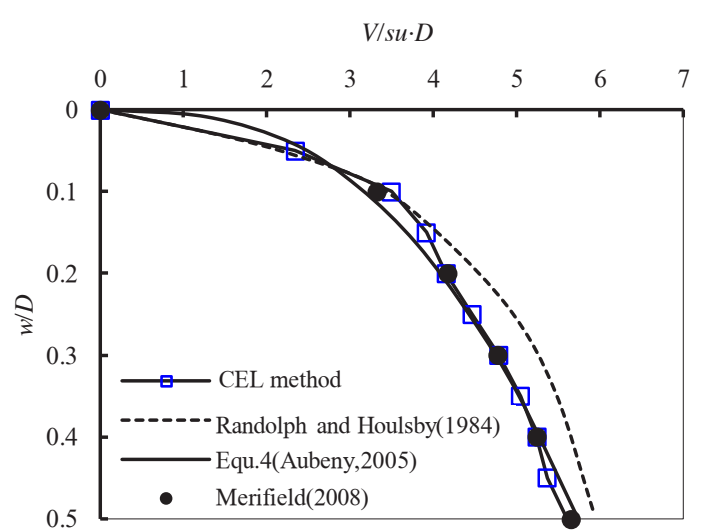

(a) rough interface

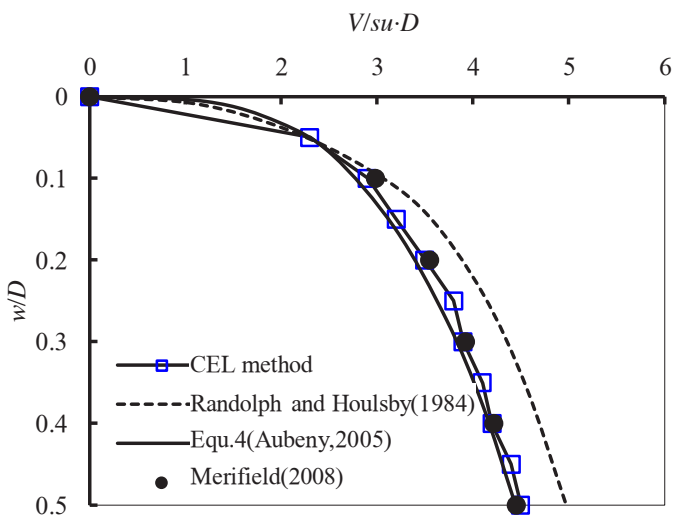

(b) smooth interface

Fig.3 Finite Element Calculation Results of Non-heavy Homogenous Soil

During the subsidence of submarine pipe, the of soil mass deformation vector map is shown in Fig.4, it can be seen that when the subsidence depth is $0.2(w / D=0.2)$, the influence range of soil mass uplift is about $1 D$; when the subsidence depth is $0.5(w / D=0.5)$, the influence range of soil mass uplift is about $2 D$.

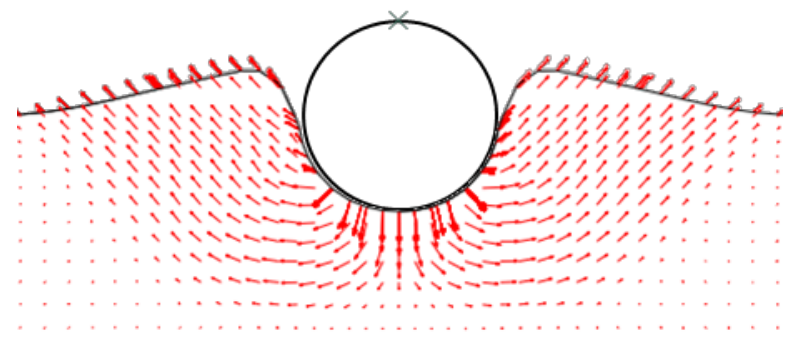

Fig.4 Vector Diagram of Deformation of Soil Mass

\subsection{Normal Heavy Consolidated Clay}

For heavy clay, the soil uplift as shown in Fig.1 and Fig.4 (b) will increase the vertical resistance of the pipe during the process of submarine pipe subsidence. In this case, the CEL finite element method is used to calculate and analyze the subsidence of the submarine pipe in the normal heavy consolidated clay foundation. In this case, the submarine self-subsidence is calculated and analyzed in the heavy weight homogeneous clay foundation by using CEL finite element method. In the calculation, 
taking the diameter of pipe $D=0.8 \mathrm{~m}$, the undrained shear strength of the soil increases linearly with depth, i.e., $s_{u 0}=s_{u m}+k z$, where $s_{u m}=2.3 \mathrm{kPa}, k=3.6 \mathrm{kPa} / \mathrm{m}$, and the effective bulk density of soil mass $\gamma^{\prime}=6.5$ $\mathrm{kN} / \mathrm{m}^{3}$. The finite element calculation model is the same as above and will not be mentioned repeatedly here.

For this soil condition, Chatterjee et al. ${ }^{[8]}$ adopted the RITSS finite element method to calculate the submarine pipe subsidence, Tian et al. ${ }^{[15]}$ adopted the "mesh-tomesh solution mapping" method carried in ABAQUS, and used the Python program to capture the position of the key node of the soil mass during the pipe subsidence, so as to solve the problem of large deformation of the soil mass. By using the CEL finite element method, the smooth and rough contact situation of pipe soil are considered and compared with the theoretical solution of formula (1). The results are shown in Fig.5. As can be seen from the figure, the results of the CEL finite element method are in good coincidence level with the theoretical solution, and the results of Chatterjee et al. ${ }^{[8]}$ and Tian et al. ${ }^{[15]}$ are exactly between the results of the smooth interface and the rough interface of the pipe-tosoil. It can be seen that the CEL finite element method has a good applicability in simulating the interaction between pipe and soil, and can effectively simulate the large deformation between submarine pipe and soil mass. The formula (1) is relatively reasonable and reliable in predicting the depth of subsidence of submarine pipe.

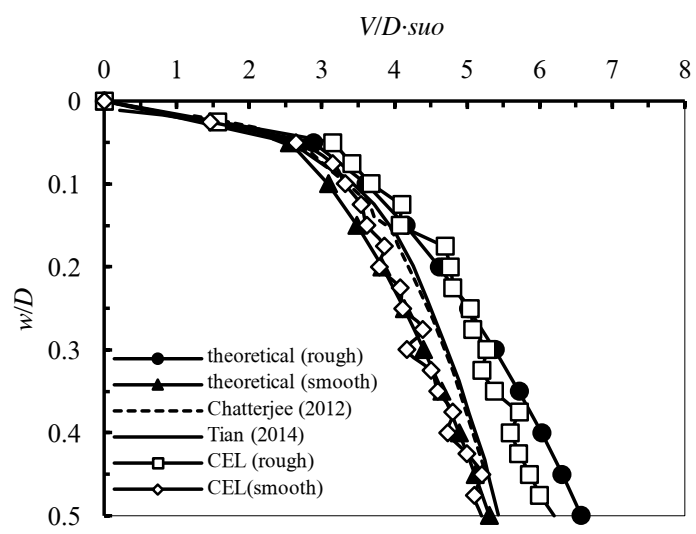

Fig.5 Calculation Results of Normal Heavy Consolidated Clay

\section{Conclusions}

Accurate prediction of deep burying after pipe installation is the key to evaluate the lateral stability of pipe. In this paper, the PIP situation of submarine pipe subsidence is studied, the relationship between the subsidence resistance and the subsidence displacement of the submarine pipe in both the non-heavy homogeneous clay and the normal heavy consolidated clay is obtained by using CEL finite element method. The study shows that the normalized vertical force $V / D s_{u}$ and normalized subsidence displacement $w / D$ calculated by the CEL finite element method in the non-heavy homogeneous soil are very close to those calculated by formula (7) and Merifield et al.. For the normal heavy consolidated clay, the uplift of soil bulk density will lead to the increase of subsidence resistance, and the calculated results by CEL finite element method are in good coincidence level with the theoretical solution shown in formula (1). At the same time, the study also shows that the CEL finite element method has a good applicability to simulate the pipe-soil interaction, and can effectively simulate the large deformation between submarine pipe and soil mass.

\section{References}

1. Merifield R, White D J, Randolph M F. The ultimate undrained resistance of partially embedded pipelines, Géotechnique, 58(6): 461-470, (2008)

2. Murff J D, Wagner D A, Randolph, M F. Pipe penetration in cohesive soil, Géotechnique, 39(2): 213-229,(1989)

3. Aubeny C P, Shi H, Murff J D. Collapse load for cylinder embedded in trench in cohesive soil, International Journal of Geomechanics, 5(4): 320325, (2005)

4. Randolph M F, White D J. Upper bound yield envelopes for pipelines at shallow embedment in clay, Géotechnique, 58(4): 297-301 (2008)

5. Cathie D N, Jaeck C, Ballard J C, et al.Pipeline geotechnics: State-of-the-art, Proc., Int. Symp. on Frontiers in Offshore Geotechnics, 95-114 (2005)

6. White D J, Gaudin C, Boylan N, et al. Interpretation of T-bar penetrometer tests at shallow embedment and in very soft soils, Canadian Geotechnical Journal, 47(2): 218-229 (2010)

7. Wang D, White D J, Randolph M F. Largedeformation finite element analysis of pipe penetration and large-amplitude lateral displacement, Canadian Geotechnical Journal, 47(8): 842-856 (2010)

8. Chatterjee S, Randolph M F, White D J. The effects of penetration rate and strain softening on the vertical penetration resistance of seabed pipelines, Géotechnique, 2012, 62(7): 573-582.

9. Merifield R, White D J, Randolph M F. Effect of surface heave on respomse of partially embedded pipelines on clay, Journal of Geotechnical and Geoenvironmental Engineering, 2009, 135(6): 819829.

10. Randolph M F, White D J. Pipeline embedment in deep water: process and quantitative assessment, In Proceedings of the Offshore Technology Conference (2008)

11. Tho K K, Leung C F, Chow Y K, et al. Deep cavity flow mechanism of pipe penetration in clay, Canadian Geotechnical Journal, 49(1): 59-69 (2012)

12. Shi H, Sun J, Hossain K, et al. Offshore pipeline embedment in cohesive soil - a comparison between existing and CEL solutions, In Proceedings of the ASME 2011 30th International Conference on Ocean, Offshore and Arctic Engineering, 1-6 (2011)

13. Dutta S, Hawlader B, Phillips R. Strain softening and rate effects on soil shear strength in modeling of 
vertical penetration of offshore pipelines, In Proceedings of the 9th International Pipeline Conference, 1-8 (2012)

14. Randolph M F, Houlsby G T. The limiting pressure on a circular pile loaded laterally in cohesive soil, Géotechnique, 34(4): 613-623 (1984)

15. Tian Y, Cassidy M J, Randolph M F, et al. A simple implementation of RITSS and its application in large deformation analysis, Computers and Geotechnics, 56: 160-167 (2014) 